\title{
Experiential and instrumental attitudes:
}

\section{Interaction effect of attitude and subjective norm on recycling intention}

\begin{abstract}
Prior studies have identified key factors that influence recycling intention. However, these studies rarely pay attention to the interaction of attitude and subjective norm that influences recycling intention. This study applied a conceptual model by extending the Theory of Planned Behavior (TPB) for addressing the gap. The study collected 246 responses through a street survey in Hong Kong. Findings revealed that two interaction terms (i.e., experiential attitude and subjective norm; instrumental attitude and subjective norm) influenced recycling intention. It implies that subjective norm plays a crucial role in motivating recycling behaviors. Moreover, subjective norm could increase the likelihood of recycling for people exhibiting positive experiential attitude, and motivate people who possesses limited knowledge on recycling benefits of practicing recycling behaviors. Policy implications were drawn from the findings. Limitations of the study and future research direction were also discussed.
\end{abstract}

Keywords: moderation; social influence; waste management; policy; Hong Kong

\section{Introduction}

Recycling is a sustainable effort to reduce human impacts on the environment that plays a critical role within the waste management hierarchy (Chen \& Tung, 2009). In this connection, governments worldwide have launched various schemes to address the issue and promote 
recycling practices among people (Wilson, Rodic, Scheinberg, Velis, \& Alabaster, 2012). Government interventions vary from legislation to voluntary programs, for example, mandatory recycling policies, waste charging schemes, provision of curbside recycling collection, setting up waste separation bins within communities, and promotional campaigns for marketing recycling practices (De Jaeger, Eyckmans, Rogge, \& Van Puyenbroeck, 2011; Goddard, 1995; Tencati, Pogutz, Moda, Brambilla, \& Cacia, 2016; Wilson, 1996). A large majority of these schemes rest on the idea of transforming recycling behaviors into a more normalized activity and motivating people to regularly participate in recycling practices (Thomas \& Sharp, 2013). For the purpose of boosting recycling intention and thereby recycling behaviors, it is crucial for both scholars and policy-makers to gain a thorough understanding of individuals' behavioral intentions to recycle.

The importance of recycling has been directing researchers to investigate the determinants of recycling intention. The Theory of Planned Behavior (TPB) (Ajzen, 1991), which comprises attitude, subjective norm, and perceived behavioral control, is a theory widely used for predicting and explaining a wide range of intentions and behaviors (Armitage \& Conner, 2001). TPB suggested that an individual's intention to perform a behavior is driven by positive evaluation of the behavior (attitude), social pressure encouraging the behavior (subjective norm) and perceived ease of performing such behavior (perceived behavioral control). To enhance TPB's predictive power, scholars have added other driving factors such as moral norm and awareness of consequences into TPB. In prior recycling studies, individuals' moral considerations to recycle (moral norm) and perceived recycling benefits (awareness of consequences) have been proved to be significant factors influencing recycling intention (Chen \& Tung, 2009; Tonglet, Phillips, \& Read, 2004). Nonetheless, prior studies rarely examined interaction effects of subjective norm and other TPB components on 
recycling intention. It was only until recently Huffman, Van Der Werff, Henning, and Watrous-Rodriguez (2014) proved that the interaction of subjective norm and utilitarian attitude of recycling (i.e., benefits of recycling) has a significant influence on recycling intention. However, before the examination of interaction effects on recycling intention can go forward, there is a need for conceptual clarification of attitude. On the one hand, Ajzen (1991, 2002) and Ajzen and Driver (1992) suggested that attitude, an individual's subjective evaluation of a behavior, comprises two components, i.e., experiential (affective; feelings) and instrumental (knowledge; function) components. Experiential attitude is an individual's affective feelings toward behavior (e.g., recycling is good behavior); whereas instrumental attitude refers to an individual's evaluation of behavior's outcomes (e.g., recycling could reduce landfill burden). On the other hand, Kaiser (2006) determined that attitude and moral norm lack discriminant validity. Chan and Bishop (2013) also proved that moral norm could substitute for attitude to predict recycling intention. Hence, how recycling intention would be influenced by the interaction effects of subjective norm and moral norm (as a possible substitute for attitude) remain unknown, and to our best knowledge no prior study has explored the issue. Therefore, there is a knowledge gap in connection to the interaction effects of subjective norm and the two components of attitude and moral norm on recycling intention.

The main objective of present study is to analyze the interaction of subjective norm and attitudinal factors that explain recycling intention. In particular, this study will first review prior studies on recycling intention and behaviors. Then, the paper will further clarify and explain two components that comprise attitude toward behavior. To address the knowledge gap, this paper investigates the interaction effects of subjective norm and attitude on 
recycling intention by analyzing results of a street survey conducted in Hong Kong. Finally, research findings and policy implications will be discussed.

\section{Literature Review and the Conceptual Model}

\subsection{Prior Study on Recycling Intention}

Recycling intention refers to an individual's self-commitment to engage in recycling behaviors (Park \& Ha, 2014). Literature has explored recycling intention by drawing variables and models from social psychology. Theory of Planned Behavior (TPB) proposed by Ajzen (1991) is a dominant theory used for studying recycling intention. It is an extension of Theory of Reasoned Action (TRA) (Fishbein \& Ajzen, 1975). TRA states that both attitude toward the behavior and subjective norm account for intention of performing the behavior. Attitude reflects an individual's subjective evaluation of the behavior. The intention to act regarding the behavior would be higher if an individual favors that behavior. Subjective norm refers to perception of social pressure from important others. The perceived pressure from significant others to perform (or not to perform) the behavior would influence behavioral intention. Ajzen (1985) used these two constructs as a base and extended TRA by introducing the perceived behavioral control (PBC), and formed TPB to explore the intention and behavioral choices. PBC represents an individual's estimation of self-ability in completing the behavior, and it is determined by external conditions such as availability of facilities and an individual's perceived ability such as knowledge of the behavior (Do Valle, Rebelo, Reis, $\&$ Menezes, 2005). TPB reveals that behavioral intention is a function of attitude, subjective norm, and perceived behavioral control (Ajzen, 1991). Over the past decades empirical studies have adopted TPB for systematic analysis of recycling intention, and the predictive 
validity of TPB has been confirmed (Boldero, 1995; Chan, 1998; Cheung, Chan, \& Wong, 1999; Knussen, Yule, MacKenzie, \& Wells, 2004; Mannetti, Pierro, \& Livi, 2004; Park \& Ha, 2014; Ramayah, Lee, \& Lim, 2012; Sidique, Lupi, \& Joshi, 2010; Taylor \& Todd, 1995a, 1995b; Tonglet et al., 2004; Wan, Cheung, \& Shen, 2012; Wan, Shen, \& Yu, 2014).

Aside from testing the validity of the standard form of TPB, emerging studies expanded TPB by introducing additional predictors (Conner \& Armitage, 1998). Ajzen (1991) also acknowledged that TPB is flexible and open to the inclusion of additional variables if they account significantly for the explanation. Originated from Schwartz's theory (1977; Schwartz \& Howard, 1981), awareness of consequences which represents an individual's tendency to become aware of the consequences of his/her behaviors for others has been proved to be a predictor of recycling intention (Chen \& Tung, 2009; Davies, Foxall, \& Pallister, 2002; Tonglet et al., 2004; Wan et al., 2012). Follows and Jobber (2000) suggested that people are concerned with both environmental consequences and individual consequences when they decide to perform behaviors. Environmental consequences are environmental impacts associated with performing specific behaviors, for example, using refillable containers reduce the amount of garbage and benefit the environment (Follows \& Jobber, 2000). Paying attention to environmental consequences involves an evaluation of one's own behaviors or others' behaviors with consequences for the environment (Fransson \& Gärling, 1999). The notion is similar to awareness of consequences for biosphere, which was found positively contributing to pro-environmental behavioral intentions (Gärling, Fujii, Gärling, \& Jakobsson, 2003; Stern, Dietz, Kalof, \& Guagnano, 1995). Individual consequences, by contrast, are personal cost and benefit for taking an action, such as time consumed for separating recycling materials and money saved by reducing energy consumption. In other words, they are utilitarian outcomes which involve rewards and punishments that follow from performing 
specific behaviors (Fransson \& Gärling, 1999). The self-related consequences were found negatively affecting intention of pro-environmental actions including recycling behavioral intention (Dahab, Gentry, \& Su, 1995; Follows \& Jobber, 2000). According to the economic assumption of rationality, individuals would maximize benefit and minimize cost by selecting an alternative with the most positive behavioral consequences (Bamberg \& Schmidt, 2003; Thøgersen, 1996). Therefore, recycling behaviors through intention is a result of a trade-off between environmental and individual consequences (Follows \& Jobber, 2000).

Aside from the individual's awareness of environmental or societal benefits of recycling, Thøgersen (1996) argued that environment-friendly behaviors are not only driven by calculation of cost and benefit but by moral beliefs as well. Motives of selfless and altruistic nature should take a role to explain such actions (Botetzagias, Dima, \& Malesios, 2015; Saphores, Ogunseitan, \& Shapiro, 2012). Manstead (2000) and Smallbone (2005) explained that TPB does not consider moral aspects because many behaviors are not activated solely by cost-benefit calculation as TPB suggests. As a result, prior studies have included moral norm to TPB accompanied with a justification that performing recycling behaviors involve moral considerations (Chan \& Bishop, 2013; Chen \& Tung, 2009; Davies et al., 2002; Tonglet et al., 2004). Moral norm is defined as a belief of right or wrong for performing a specific behavior, as well as refers to a feeling of obligation that people hold, which governs engagement of certain behaviors (Bamberg \& Möser, 2007; Harland, Staats, \& Wilke, 1999; Manstead, 2000; Schwartz, 1977; Tonglet et al., 2004).

Although individuals' values, such as self-transcendence, self-enhancement and general environmental concerns, play roles in explaining pro-environmental behaviors, these broad values are predictors of specific attitudes that indirectly influence behavioral intentions (Do 
Valle et al., 2005; Follows \& Jobber, 2000; Roccas, Sagiv, Schwartz, \& Knafo, 2002; Vining \& Ebreo, 1992). A number of prior studies have also examined the inter-relationships between the TPB factors (Bamberg, Hunecke, \& Blöbaum, 2007; Cheung et al., 1999; Knussen et al., 2004; Mahmud \& Osman, 2010). Nevertheless, to examine the interaction effect of attitude and subjective norm on recycling intention, this study adopts a parsimonious baseline model extended from TPB (Figure 1).

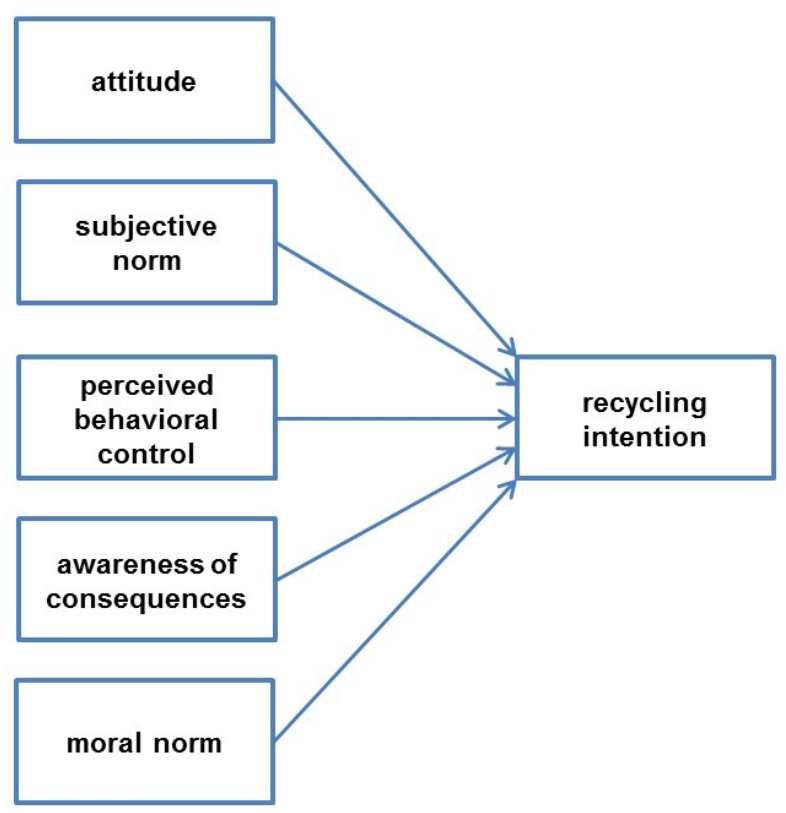

Figure 1 Factors that influence recycling intention in prior studies

\subsection{Experiential and instrumental attitudes}

Attitude is conceptualized as a multidimensional notion (Voss, Spangenberg, \& Grohmann, 2003). Ajzen (2002) suggested that measuring attitude should include both experiential (feeling; affective) and instrumental (benefits; functions) dimensions. Many studies defined attitude in terms of the experiential dimension (i.e., feeling; affective) (Chen \& Tung, 2009; 
Cheung et al., 1999; Knussen \& Yule, 2008; Knussen et al., 2004; Mannetti et al., 2004; Tonglet et al., 2004). Attitude in these studies is often operationalized by asking respondents to rate the behavior in question in a form like it is good, sensible, pleasant, or rewarding, among others. Batra and Ahtola (1991) labeled this set of affective feelings as the hedonic dimension of consumer attitude. According to a study by Voss et al. (2003) on consumer attitude, this type of attitude dimension is derived from the experiences of consumers using products. Aside from affective dimension, Ajzen and Driver (1992) argued that instrumental dimension should be considered when assessing attitude toward the behavior. Indeed, another dimension that drives consumers to perform purchasing behaviors is utilitarian purposes (i.e., instrumental) (Batra \& Ahtola, 1991). Voss et al. (2003) suggested that instrumental attitude is sourced from functions performed by products. That is, the degree of utility of a product would influence consumption attitude. In previous recycling studies (e.g., Chen and Tung (2009) and Tonglet et al. (2004)), instrumental attitude is assessed from a utilitarian perspective by asking questions such as "recycling can save energy" and "recycling benefits the environment." The items mainly focus on functions and consequences that would result from performing recycling behaviors. The instrumental aspect of attitude is often labeled as awareness of consequences that refer to the outcomes and cost-benefits of recycling behaviors (Chen \& Tung, 2009; Davies et al., 2002; Do Valle et al., 2005; Tonglet et al., 2004). Based on these research results, it is reasonably to suggest that both dimensions for assessment should be included for examination to obtain a comprehensive understanding of individuals' attitude toward recycling behaviors.

Ajzen and Driver (1992) and Davies et al. (2002) emphasized the importance of disaggregating the two dimensions when assessing attitude toward behavior. Several rationales have been provided by these studies. First, positive instrumental attitude may be 
offset by negative feelings toward a given behavior; however, positive experiential attitude could also be cancelled by negative functions projected by that the behavior (Ajzen \& Driver, 1992). Therefore, assessing by combining the dimensions of attitude in a single factor may fail to provide scholars with an accurate representation of attitude. Second, Davies et al. (2002) explained that different measurement scales and procedures may be required because of the distinct nature of attitude. The two dimensions of attitude should be measured in separated constructs (Wan et al., 2014). Voss et al. (2003) studied customer attitude and credited the separation of measuring attitude by justifying that marketers could analyze the effectiveness of experiential (affective) or instrumental (functional) advertising strategies. This idea applies to the investigations of recycling intention in which the analysis of the different dimensions of attitude enables policymakers to tailor policies that are consistent with favorable attitudes. For example, public authorities may encourage citizens to perform recycling behaviors by empathizing on feelings (i.e., good, rewarding, etc.) or consequences (i.e., saving resources, reducing pollution, etc.).

\subsection{Moral norm as a substitute for attitude}

Previous section indicated that moral norm is incorporated into TPB to predict recycling intention (Chen \& Tung, 2009; Harland et al., 1999; Tonglet et al., 2004). Moral norm in these studies serves as an independent and additional predictor of intention. Harland et al. (1999) proved that moral norm significantly increases variance to explain behavioral intentions in different contexts. Wan et al. (2014) suggested that measuring moral norm from attitudes would provide a considerably precise conceptual distinctiveness. By contrast, Kaiser, Doka, Hofstetter, and Ranney (2003) argued that moral norm has already been included and represented in the attitude of individuals. Kaiser (2006) further determined that attitude and 
moral norm are substantially correlated to each other in the conservation behavior context, and that two factors lack discriminant validity in between. Turaga, Howarth, and Borsuk (2010) argued that although moral norm is an important factor that influences proenvironmental behaviors, no consensus has been reached on how this factor should be formulated in TPB.

To investigate further the role of moral norm in explaining recycling retention, Chan and Bishop (2013) compared variations of the TPB models, which considered moral norm as (1) additional predictor, (2) antecedent of attitude, and (3) substitute for attitude. They showed that the model with moral norm as a substitute for attitude is statistically fit and the most parsimonious. However, Botetzagias et al. (2015) presented a different conception in which moral norm has resembling direct influence on recycling intention, which is similar to intention created by the construct attitude. However, the hypothesis of moral norm as a substitute of attitude is rejected. The contextual differences in the aforementioned studies, that is, Australia and Greece, respectively, may account for the differing results of the two studies. Therefore, no consensus has been reached whether moral norm could be a replacement of attitude.

\subsection{Interaction effect of subjective norm and attitudes}

In TPB, social influence is represented by the concept of subjective norm (White, Smith, Terry, Greenslade, \& McKimmie, 2009). It stresses on the perception of influence and pressure from significant others that have effects on behavioral intention of individuals (Ajzen, 1991). Subjective norm in the TPB shares a similar meaning with injunctive norm

which was proposed by (Cialdini, Kallgren, \& Reno, 1991). Both notions refer to an 
individual's perception of relevant others' beliefs that the individual should or should not perform specific behaviors in a given context. They are prescriptive social influence because individuals are told what should or should not be done via the means of social norms (Fornara, Carrus, Passafaro, \& Bonnes, 2011; White et al., 2009). Hornik, Cherian, Madansky, and Narayana (1995) grouped this type of social influence as an example of extrinsic incentives of performing behaviors, and our actions in response to social influence are results of a series of conscious decision-making processes (Comber \& Thieme, 2013).

The major source of social influence comes from important others of an individual such as family members, friends, and neighbors (Ajzen, 1991; Cialdini et al., 1991; Vining \& Ebreo, 1990); these important others serve as evaluators on individuals' behaviors (Comber \& Thieme, 2013). People act in response to social norms because they would like to obtain approval from relevant others while avoiding blame from others (Cialdini et al., 1991; Comber \& Thieme, 2013; White et al., 2009). Moreover, social influence is not unidirectional but can operate via various means, for instance, mass media and environmental groups are alternative channels which can exert influence on individuals (Chan, 1998). According to the notion of collective self, an individual would assess his own behaviors by drawing reference to collective groups around (White et al., 2009, p. 138). Behavioral adjustment would then be made with reference to situational cues if the individual possesses a strong sense of selfmonitoring. Hence, the existence of others is a precondition of inducing changes in behavioral intentions (Comber \& Thieme, 2013; White et al., 2009).

Recycling behaviors are visible activities which exert social pressure for a positive effect on further recycling behaviors. It facilitates the establishment of new norms and, in turn, the normative information is an effective and powerful form of social influence which can 
motivate a change in behavior (Nolan, Schultz, Cialdini, Goldstein, \& Griskevicius, 2008; Thomas \& Sharp, 2013). Correlation between the established subjective norm and recycling intention has been empirically proved in various studies (Hornik et al., 1995). For example, Cheung et al. (1999) empirical determined that subjective norm substantially predicts the intention of wastepaper recycling. Similar results can also be found in research by Chen and Tung (2009), Comber and Thieme (2013), Knussen et al. (2004), Mannetti et al. (2004), Ramayah et al. (2012), and Sidique et al. (2010).

Although direct relationships between recycling intention and its causal factors are proved in the majority of empirical studies that mentioned in previous sections, interaction effects between different causal factors on recycling intention may be more complicated than the literature has suggested. Recently, Huffman et al. (2014) empirically determined that the interaction effect of recycling instrumental attitude and subjective norm significantly influences recycling intention. In addition, for people who carry weak recycling attitude, strong subjective norm would substantially boost their intention to perform recycling behaviors. In other psychological fields, the interaction effect of subjective norm and attitude has been extensively investigated and discussed. Povey, Conner, Sparks, James, and Shepherd (2000) showed that the intention of healthy eating would be strong if individuals perceive a high level of social influence and favored healthy eating. In e-learning and tourism studies, Cheung and Vogel (2013) and Lam, Baum, and Pine (2003) suggested that if both subjective norm and attitude are strong, individuals would have strong intention to perform certain behaviors. It is evident from research that subjective norm may interact with attitude and its interaction effect may exert influence on recycling intention. However, these studies focus only on one dimension of attitude (i.e., instrumental attitude), which is included in the 
study by Huffman et al. (2014), whereas Cheung and Vogel (2013), Lam et al. (2003), and Povey et al. (2000) only measured experiential attitude.

Huffman et al. (2014) also explained that the interaction effect of subjective norm and instrumental attitude would negatively influence recycling intention. When individuals perceive strong social influence that encourages them to recycle, the effect of instrumental attitude becomes considerably irrelevant. By contrast, studies from other psychological fields suggested that the interaction term of subjective norm and experiential attitude positively influence behavioral intention (Cheung \& Vogel, 2013; Lam et al., 2003; Povey et al., 2000). This view could be identified when an individual perceives strong social influence and carries positive feelings toward recycling, thereby making the intention to perform certain behaviors considerably strong. Finally, as discussed in preceding section moral norm could be a substitute of attitude (Chan \& Bishop, 2013; Kaiser, 2006). Chan and Bishop (2013) and Botetzagias et al. (2015) analyzed whether moral norm could replace experiential attitude. In relation to this notion, the interaction term of subjective and moral norms positively influences recycling intention. Thus, the following hypotheses are proposed.

Hypothesis 1 (H1): The interaction of subjective norm and experiential attitude (termed as attitude) positively influences recycling intention.

Hypothesis 2 (H2): The interaction of subjective norm and instrumental attitude (termed as awareness of consequences) negatively influences recycling intention.

Hypothesis 3 (H3): The interaction of subjective norm and moral norm positively influences recycling intention. 
Figure 2 shows the conceptual model to be tested in this study.

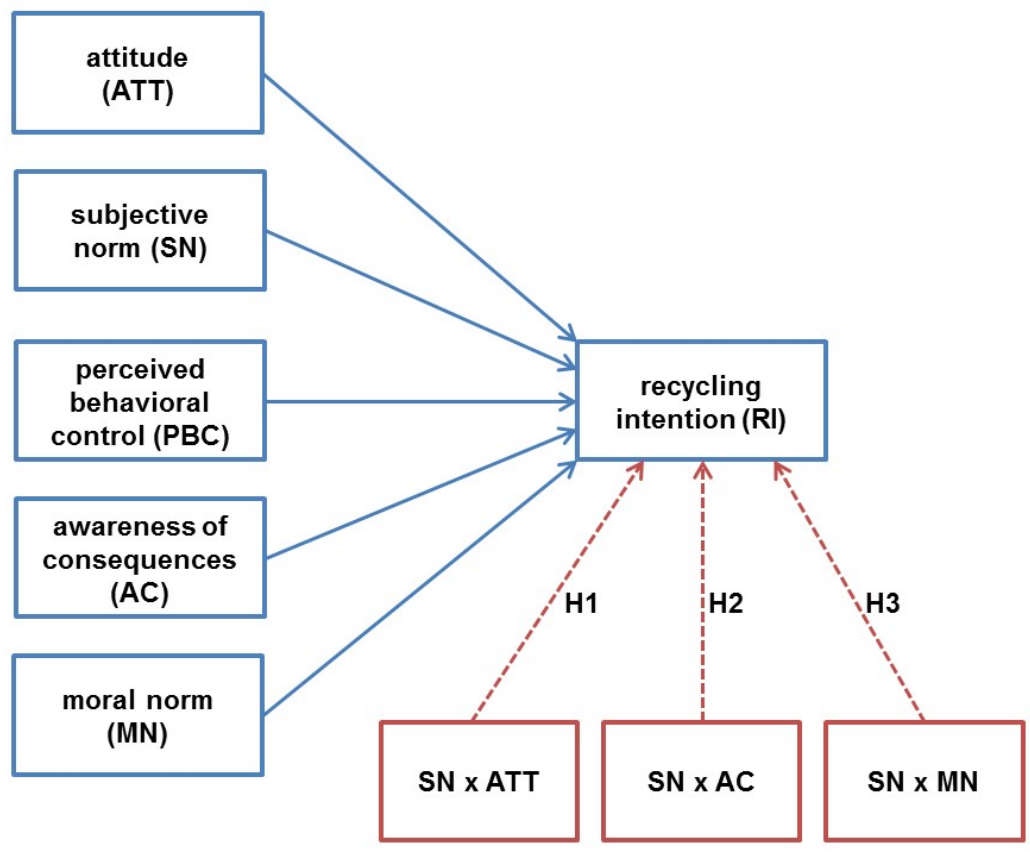

Figure 2 Conceptual model

\section{Methods}

\subsection{Measures}

The measures used in this study, namely, attitude, subjective norm, PBC, awareness of consequence, moral norm, and recycling intention, were adopted from Tonglet et al. (2004), Sidique et al. (2010), and Wan et al. (2012). All measurement items were on a seven-point scale, where 7 indicated the most positive view and 1 indicated the most negative view (i.e., 1 $=$ strongly disagree; $7=$ strongly agree). The items are shown in Appendix 1. The questionnaire also included questions on respondent's demographic information. A pilot test 
was organized in which 20 copies of the questionnaire were distributed to students and staff members in a university in Hong Kong. Thereafter, several wordings in the questionnaire were refined according to comments provided by the respondents.

\subsection{Sampling and data collection}

For the purpose of recruiting both recyclers and non-recyclers in the sampling, Belton, Crowe, Matthews, and Scott (1994) recommended that a recycling survey should be conducted in busy sites. In addition, stratified sampling can be used for identifying a wide range of selected geographic locations (i.e. strata) that are representatives of certain characteristics (Bator, Bryan, \& Schultz, 2010). Following the suggestions, the survey was administered in six sites covering three main regions in Hong Kong. Four easily accessible shopping malls drawn from a list in the study by Yiu and $\mathrm{Xu}$ (2012) and two railway stations located in considerably busy residential and commercial areas (Census and Statistics Department, 2011) were chosen for this purpose. Given that each region in the city possesses different demographic characteristics (i.e. educational level, age, income) (Census and Statistics Department, 2011), therefore the sites were selected to represent varying levels of the demographic differences. Replicated from administration mode suggested by González-Torre and Adenso-Díaz (2005) on recycling survey, a total of 246 respondents were randomly interviewed in these sites. The respondent profile will be presented in the following section.

\subsection{Statistical analysis}

Structural equation modeling (SEM) measures relationships between unobserved constructs based on their assigned indicators (Chin, 1998a; Jöreskog \& Sörbom, 1989). There are two 
major statistical approaches for structural equation models estimations: Hair, Ringle, and Sarstedt (2011) suggested that covariance-based and variance-based partial least squares (PLS) approaches are the two major SEM estimation approaches. While covariance-based SEM is theory confirmation or comparison of theories, PLS is considerably suitable for theoretical development for numerous relationships to be tested and for studies with small sample sizes (Hair et al., 2011; Jöreskog \& Wold, 1982; Lu, Kwan, Thomas, \& Cedzynski, 2011; Reinartz, Haenlein, \& Henseler, 2009). PLS is substantially suitable in the current study because (1) the key objective of this study is to investigate the interaction effect of subjective norm and attitudinal factors, and a high number of casual relationships is to be tested in the model (Henseler, Ringle, \& Sinkovics, 2009); and (2) the sample size of the present study is relatively small for covariance-based SEM. The statistical software SmartPLS 2.0 (Ringle, Wende, \& Will, 2005) was used for the PLS analysis.

\section{4. $\quad$ Findings}

\subsection{Respondent Profile}

There were 246 valid responses obtained from the street survey described in the earlier section. Respondent profile is presented in Table 1. 
Table 1 Respondent Profile

\begin{tabular}{lcc}
\hline Demographic Variable & N & \% \\
\hline Gender & 115 & $46.75 \%$ \\
Male & 131 & $53.25 \%$ \\
Female & & \\
\hline Age & 9 & $3.66 \%$ \\
$18-19$ & 83 & $33.74 \%$ \\
$20-24$ & 50 & $20.33 \%$ \\
$25-29$ & 48 & $19.51 \%$ \\
$30-34$ & 10 & $4.07 \%$ \\
$35-39$ & 12 & $4.88 \%$ \\
$40-44$ & 17 & $6.91 \%$ \\
$45-49$ & 17 & $6.91 \%$ \\
50 or above & & \\
\hline Education Level & 22 & $8.94 \%$ \\
Primary & 9 & $3.66 \%$ \\
Lower Secondary & 71 & $28.86 \%$ \\
Upper Secondary & 44 & $17.89 \%$ \\
Sub-degree & 89 & $36.18 \%$ \\
Bachelor's Degree & 11 & $4.47 \%$ \\
Master's or above & & \\
\hline Monthly Income (HK\$) & 95 & $38.62 \%$ \\
Below 9999 & 92 & $37.40 \%$ \\
10,000-19,999 & 31 & $12.60 \%$ \\
20,000-29,999 & 20 & $8.13 \%$ \\
30,000-39,999 & 4 & $1.63 \%$ \\
40,000-49,999 & 4 & \\
Above 50,000 & & \\
\hline
\end{tabular}

According to the rule of thumb suggested by Hair et al. (2011), sample size for the PLS analysis should be at least 10 times the largest number of hypothesized relationships directed to a particular dependent variable. Figure 2 shows that 8 paths are directed to the dependent variable, that is, recycling intention. Hence, the minimum sample size required is $8 \times 10$, which corresponds to 80 . Alternatively, the required sample size can be obtained by performing statistical power analysis based on significance level of hypothesis testing $(\alpha)$, effect size $\left(f^{2}\right)$, and the number of paths directed to the dependent variable $\left(n_{p}\right)$ (Akter, D'Ambra, \& Ray, 2011; Cohen, 1988). We have used software G*Power 3.1 (Faul, Erdfelder, Lang, \& Buchner, 2007) that the sample size required is $160\left(\alpha=0.05 ; \mathrm{f}^{2}=0.15 ; \mathrm{n}_{\mathrm{p}}=8\right)$. The selected effect size for this study is 0.15 indicating that the statistical analysis would be able to identify significance of relationships with medium level of strength (Cohen, 1988); and it 
is frequently used and adequate to discover important causal relationships (Akter et al., 2011). Overall, the sample size of 246 is statistically adequate.

\subsection{Measurement Model}

PLS analysis was accomplished in two steps (Chin, 1998b), that is, assessing the measurement and structural models separately. First, convergent validity, discriminant validity, and composite reliability of indicators were analyzed for evaluation of the PLS measurement model. Convergent validity and composite reliability assessed the correlation between the indicators within the same constructs. The following criteria would be judged when evaluating measurement scales (Chin, 1998b; Fornell \& Larcker, 1981): (1) factor loadings of all indicators should be greater than 0.5 , (2) composite reliability value should be greater than 0.7, and (3) the average variance extracted (AVE) of each construct should be greater than 0.5 . Cronbach's alpha score is a common measure to determine the internal reliability of each construct, that is, intercorrelations among indicators within a construct. Hair, Black, Babin, and Anderson (2013) suggested that Cronbach's alpha of each construct should be greater than 0.7 . Table 2 shows that all the constructs fulfilled the statistical criteria for convergent validity.

Table 2 Measurement model

\begin{tabular}{lcccc}
\hline Constructs & $\begin{array}{c}\text { Factor } \\
\text { loadings }\end{array}$ & $\begin{array}{c}\text { Average } \\
\text { variance } \\
\text { extracted }\end{array}$ & $\begin{array}{c}\text { Composite } \\
\text { reliability }\end{array}$ & $\begin{array}{c}\text { Cronbach's } \\
\text { alpha }(\boldsymbol{\alpha})\end{array}$ \\
\hline Attitude & 0.910 & 0.847 & 0.971 & 0.964 \\
$($ ATT) & 0.946 & & & \\
& 0.956 & & \\
& 0.878 & & 0.893 \\
& 0.946 & & \\
\hline Subjective Norm & 0.885 & 0.646 & & \\
(SN) & 0.856 & & & \\
& 0.838 & & & \\
\hline
\end{tabular}




\begin{tabular}{|c|c|c|c|c|}
\hline & $\begin{array}{l}0.817 \\
0.820\end{array}$ & & & \\
\hline $\begin{array}{l}\text { Perceived Behavioral Control } \\
\text { (PBC) }\end{array}$ & $\begin{array}{l}0.854 \\
0.899 \\
0.873 \\
0.760 \\
0.852 \\
0.894 \\
0.832 \\
\end{array}$ & 0.728 & 0.949 & 0.938 \\
\hline $\begin{array}{l}\text { Awareness of Consequences } \\
\text { (AC) }\end{array}$ & $\begin{array}{l}0.874 \\
0.878 \\
0.919 \\
0.873 \\
0.768 \\
0.893\end{array}$ & 0.755 & 0.949 & 0.935 \\
\hline $\begin{array}{l}\text { Moral Norm } \\
(\mathrm{MN})\end{array}$ & $\begin{array}{l}0.897 \\
0.913 \\
0.942 \\
0.932 \\
0.879 \\
\end{array}$ & 0.833 & 0.961 & 0.950 \\
\hline $\begin{array}{l}\text { Recycling Intention } \\
\text { (RI) }\end{array}$ & $\begin{array}{l}0.965 \\
0.952 \\
0.955\end{array}$ & 0.916 & 0.970 & 0.954 \\
\hline
\end{tabular}

Moreover, the discriminant validity evaluates whether indicators are unique for one construct and distinct from other indicators of different constructs (Campbell \& Fiske, 1959), that is, indicators measuring different constructs should not be correlated. A construct can be considered as valid if the square root of AVE of the construct exceeds the correlations between that construct and any other constructs in the model (Chin, 1998b; Fornell \& Larcker, 1981). Table 3 shows that all the constructs met the requirement.

Table 3 Correlations among the constructs

\begin{tabular}{lllllll}
\hline Constructs & ATT & SN & PBC & AC & MN & RI \\
\hline Attitude (ATT) & $\mathbf{0 . 9 2 0}$ & & & & & \\
Subjective Norm (SN) & 0.611 & $\mathbf{0 . 8 0 4}$ & & & & \\
Perceived Behavioral Control (PBC) & 0.607 & 0.646 & $\mathbf{0 . 8 5 3}$ & & & \\
Awareness of Consequences (AC) & 0.835 & 0.584 & 0.559 & $\mathbf{0 . 8 6 9}$ & & \\
Moral Norm (MN) & 0.786 & 0.731 & 0.737 & 0.712 & $\mathbf{0 . 9 1 3}$ & \\
Recycling Intention (RI) & 0.730 & 0.702 & 0.790 & 0.686 & 0.836 & $\mathbf{0 . 9 5 7}$ \\
\hline
\end{tabular}

Note: Figures in bold are the square roots of the average variance extracted (AVE). 


\subsection{Structural Model}

The second step of PLS analysis is structural model evaluation, that is, to confirm the degree of statistical significance of hypotheses specified by the proposed model. To determine significance of the hypotheses, the model is run by using a bootstrap resampling routine with cases (i.e., the 246 surveyed responses) and 1000 subsamples. This bootstrap resampling routine generates subsamples by randomly selecting a case from the data set, and the subsamples are used for assessing the significance of hypotheses (Chin, 1998b). Furthermore, $R^{2}$ values of $0.25,0.50$, and 0.75 can be read as weak, moderate, and substantial, respectively in structural model of PLS (Hair et al., 2011). Table 4 summarizes the results of the direct and interaction effects in the analysis.

Table 4 Testing Results

\begin{tabular}{|c|c|c|c|c|c|c|c|c|c|}
\hline \multirow[t]{2}{*}{ Constructs } & \multicolumn{3}{|c|}{ Model 1} & \multicolumn{3}{|c|}{ Model 2} & \multicolumn{3}{|c|}{ Model 3} \\
\hline & $\beta$ & t-value & Sig. & $\beta$ & t-value & Sig. & $\beta$ & t-value & Sig. \\
\hline$\overline{\mathrm{ATT}}$ & 0.325 & 6.101 & $* * *$ & 0.084 & 1.377 & & -0.328 & 1.394 & \\
\hline $\mathrm{SN}$ & 0.207 & 4.215 & $* * *$ & 0.096 & 2.021 & * & 0.545 & 3.834 & $* * *$ \\
\hline PBC & 0.459 & 9.594 & $* * *$ & 0.345 & 6.887 & $* * *$ & 0.381 & 7.879 & $* * *$ \\
\hline $\mathrm{AC}$ & & & & 0.101 & 1.964 & * & 0.763 & 4.005 & $* * *$ \\
\hline $\mathrm{MN}$ & & & & 0.373 & 5.286 & $* * *$ & 0.343 & 1.793 & $*$ \\
\hline $\mathrm{H} 1: \mathrm{ATT} \times \mathrm{SN}$ & & & & & & & 0.715 & 1.668 & $*$ \\
\hline $\mathrm{H} 2: \mathrm{AC} \times \mathrm{SN}$ & & & & & & & -1.351 & 3.653 & $* * *$ \\
\hline $\mathrm{H} 3: \mathrm{MN} \times \mathrm{SN}$ & & & & & & & 0.004 & 0.022 & \\
\hline $\mathrm{R}^{2}$ & & 0.745 & & & 0.783 & & & 0.800 & \\
\hline GoF & & 0.764 & & & 0.785 & & & 0.794 & \\
\hline $\mathrm{f}^{2}$ & & & & & 0.173 & & & 0.086 & \\
\hline
\end{tabular}

Model 1, which included the three variables in TPB, accounted for $74.5 \%$ of the variance in the recycling intention. Model 1 showed that the three TPB variables (i.e., attitude, subjective norm, and PBC) positively influenced recycling intention. 
Model 2 included two additional variables, namely, awareness of consequences and moral norm, which were adopted from prior studies on recycling intention. By adding the two variables, the model accounted for $78.3 \%$ of the variance in the recycling intention. All paths were significant, except for the relationship between attitude and recycling intention. Further analyses were performed by including only one additional variable into TPB at each time. Hence, attitude remained significant $(\beta=0.230, t=3.557)$ when the model included the three TPB variables and awareness of consequences. Similarly, attitude remained significant when the TPB variables and moral norm are included in the analysis $(\beta=0.157, \mathrm{t}=2.449)$. The findings could have been the effect of additional constructs to TPB, awareness of consequences, and moral norm, thereby taking over the predictive power from attitude. Cohen (1988) proposed that the effect of a latent predictor could be calculated using the following formula that is based on the value of $R^{2}$ with the proposed predictor included and excluded from the model: $\mathrm{f}^{2}=\left(\mathrm{R}^{2}{ }_{\text {incl }}-\mathrm{R}^{2}{ }_{\text {excl }}\right) /\left(1-\mathrm{R}^{2}{ }_{\text {incl }}\right)$. The values $0.02,0.15$, and 0.35 could be interpreted as small, medium, or large effect, respectively, at the structural level. The value of effect $\left(f^{2}\right)$ for the two additional paths in Model 2 was 0.173 , which indicated a medium effect.

Model 3 accounted for $80 \%$ of variance in recycling intention after the three interaction terms were included. The value of the effect $\left(\mathrm{f}^{2}\right)$ for the interaction terms was 0.086 , which represented a small-to-medium effect. The results showed that $\mathrm{H} 1$ and $\mathrm{H} 2$ were supported (but not $\mathrm{H} 3$ ). The interaction term of $\mathrm{SN} \times \mathrm{ATT}$ had a negative effect on recycling intention, whereas the interaction term of $\mathrm{SN} \times \mathrm{AC}$ had positive effect. Figures 3 and 4 show the slope analyses for the two significant interaction terms. Figure 3 shows that if an individual has a high level of experiential attitude, then a strong perception of subjective norm would cause a high level of recycling intention. Figure 4 illustrates that the awareness of consequences (i.e., 
instrumental attitude) is important to individuals who are relatively not influenced by subjective norm. However, awareness of consequences has limited relevance to individuals with a high level of subjective norm.

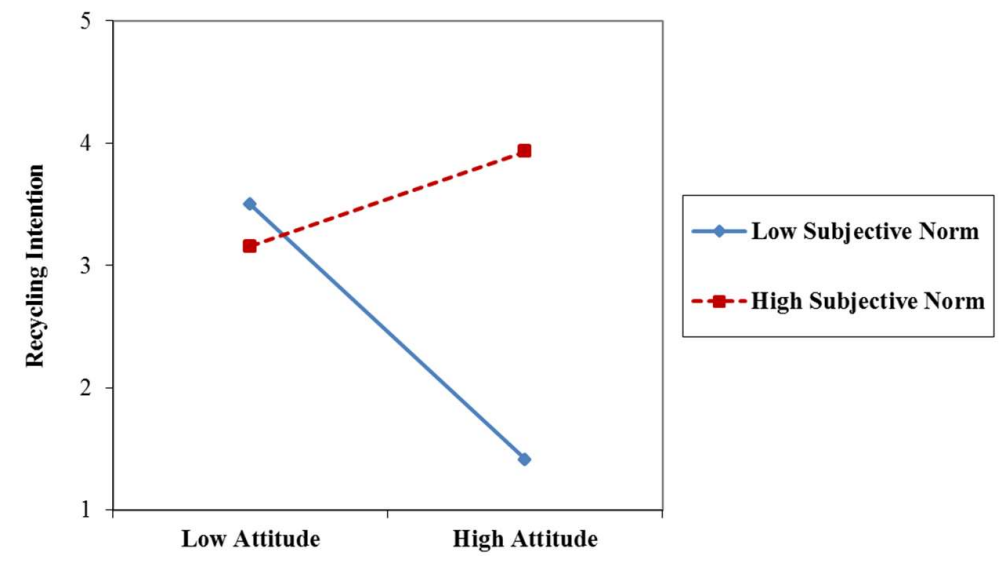

Figure 3 Interaction of the subjective norm and attitude on recycling intention

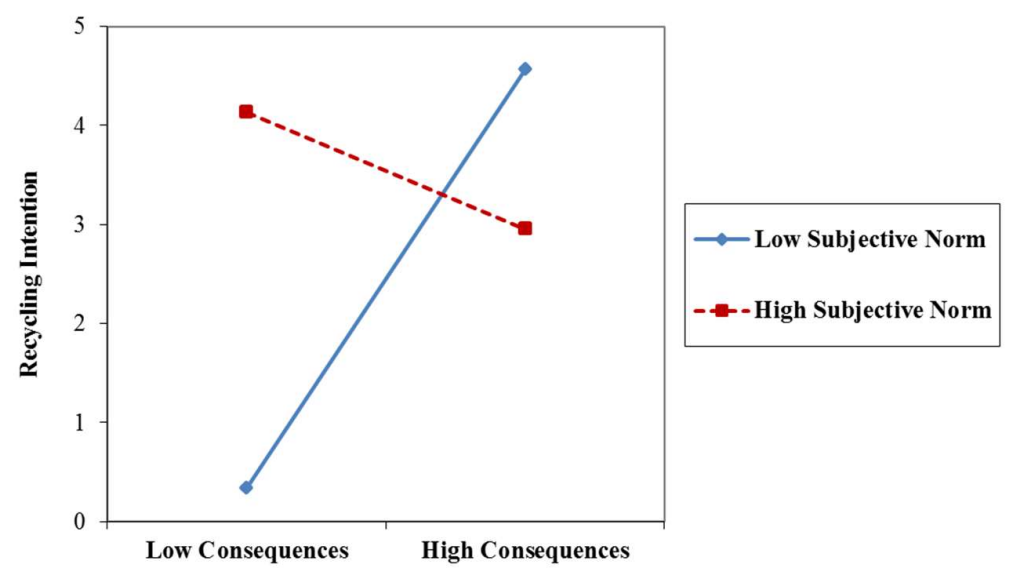

Figure 4 Interaction of the subjective norm and awareness of consequences on recycling intention

In contrast to covariance-based SEM, PLS does not provide various statistical measures for the model validation, such as $\chi^{2}$, GFI, AGFI and other model fit measures (Henseler \& 
Sarstedt, 2013). Tenenhaus, Vinzi, Chatelin, and Lauro (2005) proposed a single criterion of goodness of fit (GoF) for PLS based on the average communality and the average $\mathrm{R}^{2}$. GoF value of $0.35,0.50$, and 0.61 is considered as respectively small, medium, and large (Latan \& Ghozali, 2012). All three models were considered fit.

\section{Discussion}

TPB laid a beneficial foundation to explain recycling intention. The two additional variables (i.e., awareness of consequences and moral norm) used in prior studies increased the predictive power of TPB. The findings indicated that attitude become non-significant after the two additional factors were included. Therefore, individuals were more influenced by instrumental attitude and moral norm than experiential attitude.

The findings showed that subjective norm interacts with experiential and instrumental attitudes. In relation to experiential attitude, the interaction term positively influenced recycling intention. Hence, recycling intention would be stronger if an individual perceives high levels of experiential attitude and subjective norm. This interaction has rarely been studied in the context of pro-environmental behaviors. However, the result is similar to those in other socio-psychological studies (Cheung \& Vogel, 2013; Povey et al., 2000). Furthermore, the interaction between subjective norm and instrumental attitude negatively influenced recycling intention. This result is consistent with the study of Huffman et al. (2014), who explained that strong subjective norm could decrease the effect of instrumental attitude on recycling intention. Hence, when society or peer groups are strongly encouraging recycling, individuals would likely perform recycling regardless of their awareness of the recycling benefits. 
The practical implications for public authorities on encouraging recycling can be inferred from the obtained results. First, subjective norm is proved crucial to enhance an individual's intention to recycle. Subjective norm enhances the recycling intention of people with strong experiential attitude and those without considerable awareness of recycling benefits. Therefore, public authorities may position recycling as a social trend, such as a promotional campaign to illustrate the popularity of recycling. Furthermore, Ohanian (1990) suggested that a celebrity is a source of social influence, and promotional messages delivered by experts and trustworthy celebrities could be persuasive to the public. The two types of social norms, namely, injunctive and descriptive norms, that Cialdini et al. (1991) categorized would provide insights on the planning of promotional messages. Injunctive norms refer to behaviors commonly approved or disapproved, which is equivalent to subjective norm in TPB (Heath \& Gifford, 2002), whereas descriptive norms refer to behaviors demonstrated by most members of a particular social setting. For example, a message that encourages recycling via celebrities could be an injunctive norm information, whereas that showing the frequency or percentage of the local population performing recycling would be descriptive norm information. Schultz, Nolan, Cialdini, Goldstein, and Griskevicius (2007) indicated that the relative strength of persuasive appeal between descriptive and injunctive norms is inconclusive. Therefore, a message should include both types of norm information.

In this study, two interaction effects (i.e., attitude and subjective norm; awareness of consequences and subjective norm) were determined to have a significant role in influencing recycling intention. Although the coefficients of the interaction term of experiential attitude (attitude) and subjective norm were positively significant, the interaction term of instrumental attitude (awareness of consequences) and subjective norm was negative. The interaction plot 
(Figure 3) indicates that if an individual perceives a high level of subjective norm and experiential attitude, recycling intention would be further enhanced. Therefore, subjective norm plays an important role in encouraging people to recycle. In relation to instrumental attitude, the negative interaction term could be interpreted such that instrumental attitude plays a less important role for people perceiving strong subjective norm. Hence, Figure 4 illustrates that instrumental attitude would play an important role for individuals with low subjective norm level. This result suggested that intervention strategies for individuals with high and low subjective norms should be differentiated. For individuals with high subjective norm, the provision of information on the positive environmental and societal benefits of recycling would be ineffective. However, individuals with low subjective norm, such as information provision, would be substantially effective. Overall, promoting recycling behaviors as a social trend, rather than highlighting benefits, may be a considerably effective approach. Social influences are recognized by members of a group or society, and govern behaviors of individuals (Cialdini \& Trost, 1998). These principles and rules are cues for individuals to behave in an expected way. In addition, adherence to social influences receives approval from society in return (Cialdini \& Goldstein, 2004). Therefore, Abrahamse and Steg (2013) reported, desirable behaviors can be effectively achieved by means of social influences, learning, and comparison.

Future research could address the limitations of this study. The current study was conducted through a street survey in Hong Kong and the sample's selectivity of young groups (i.e., 2024, 25-29, and 30-34) may over-represent the attitudes and recycling intention of young people. Future studies could verify and validate the current results by replicating the analysis on a large and substantially representative sample. Moreover, though discriminant validity of the six constructs has been established, some constructs are likely to be inter-correlated (e.g., 
perceived behavioral control and moral norm). It is suggested that the relevant measurements need to be reexamined for a clearer conceptualization in future research. In addition, future studies would benefit from the inclusion of objective measured behaviors by observing and recording actual recycling behaviors. Current findings could be used to address the limitation of self-reported behaviors.

\section{Conclusions}

This study adopted TPB and analyzed the interaction effect of attitudes and subjective norm on recycling intention. The interaction term of experiential attitude and subjective norm positively influenced recycling intention. The interaction term of instrumental attitude and subjective norm was negatively significant in predicting recycling intention. Moreover, subjective norm plays a crucial role in motivating individuals to recycle, thereby possibly increasing the likelihood of recycling for people carrying positive experiential attitude, as well as motivating people with limited knowledge on recycling benefits to perform recycling behaviors. Practical implications were drawn based on findings that public authorities should promote recycling as a desirable social trend. The messages are suggested to provide information of injunctive (i.e., social acceptable behaviors) and descriptive (i.e., behaviors displayed by others) norms.

This study contributes to the recycling literature by clarifying the nature and role of experiential attitude, instrumental attitude, and moral norm in predicting recycling intention. Furthermore, the interaction effects of subjective norm and attitudinal factors were analyzed by applying TPB. An alternative explanation of recycling intention is provided in addition to prior studies that emphasize the direct effect of subjective norm on recycling intention. This 
study proposed promotional approaches to encourage recycling behaviors. This approach would be particularly beneficial for public authorities in cities that suffer from waste management problems. 


\section{References}

Abrahamse, W., \& Steg, L. (2013). Social influence approaches to encourage resource conservation: A meta-analysis. Global Environmental Change, 23(6), 1773-1785.

Ajzen, I. (1985). From Intentions to Actions: A Theory of Planned Behavior. In J. Kuhl \& J. Beckmann (Eds.), Action Control: From Cognition to Behavior (pp. 11-39). Berlin, Heidelberg: Springer Berlin Heidelberg.

Ajzen, I. (1991). The theory of planned behavior. Organizational Behavior and Human Decision Processes, 50(2), 179-211.

Ajzen, I. (2002). Constructing a TPB Questionnaire: Conceptual and Methodological Considerations. Working Paper, University of Massachusetts, Amherst. http://chuang.epage.au.edu.tw/ezfiles/168/1168/attach/20/pta_41176_7688352_57138.pd f

Ajzen, I., \& Driver, B. (1992). Application of the theory of planned behavior to leisure choice. Journal of Leisure Research, 24(3), 207.

Akter, S., D'Ambra, J., \& Ray, P. (2011). An evaluation of PLS based complex models: the roles of power analysis, predictive relevance and GoF index. AMCIS 2011 ProceedingsAll Submissions.

Armitage, C. J., \& Conner, M. (2001). Efficacy of the theory of planned behaviour: A meta-analytic review. British Journal of Social Psychology, 40(4), 471-499.

Bamberg, S., Hunecke, M., \& Blöbaum, A. (2007). Social context, personal norms and the use of public transportation: Two field studies. Journal of Environmental Psychology, 27(3), 190-203.

Bamberg, S., \& Möser, G. (2007). Twenty years after Hines, Hungerford, and Tomera: A new meta-analysis of psycho-social determinants of pro-environmental behaviour. Journal of Environmental Psychology, 27(1), 14-25.

Bamberg, S., \& Schmidt, P. (2003). Incentives, morality, or habit? Predicting students' car use for university routes with the models of Ajzen, Schwartz, and Triandis. Environment and Behavior, 35(2), 264-285.

Bator, R. J., Bryan, A. D., \& Schultz, P. W. (2010). Who Gives a Hoot? Intercept Surveys of Litterers and Disposers. Environment and Behavior, 43(3), 295-315.

Batra, R., \& Ahtola, O. T. (1991). Measuring the hedonic and utilitarian sources of consumer attitudes. Marketing Letters, 2(2), 159-170. doi: 10.1007/BF00436035

Belton, V., Crowe, D. V., Matthews, R., \& Scott, S. (1994). A survey of public attitudes to recycling in Glasgow (UK). Waste management \& research, 12(4), 351-367.

Boldero, J. (1995). The prediction of household recycling of newspapers: The role of attitudes, intentions, and situational factors. Journal of Applied Social Psychology, 25(5), 440-462.

Botetzagias, I., Dima, A.-F., \& Malesios, C. (2015). Extending the Theory of Planned Behavior in the context of recycling: The role of moral norms and of demographic predictors. Resources, Conservation and Recycling, 95, 58-67. doi: http://dx.doi.org/10.1016/j.resconrec.2014.12.004

Campbell, D. T., \& Fiske, D. W. (1959). Convergent and discriminant validation by the multitrait-multimethod matrix. Psychological Bulletin, 56(2), 81.

Census and Statistics Department. (2011). 2011 Population Census. Hong Kong: The Government of Hong Kong Special Adminstrative Region Retrieved from http://www.census2011.gov.hk/en/index.html.

Chan, K. (1998). Mass communication and pro-environmental behaviour: waste recycling in Hong Kong. Journal of Environmental Management, 52(4), 317-325. 
Chan, L., \& Bishop, B. (2013). A moral basis for recycling: Extending the theory of planned behaviour. Journal of Environmental Psychology, 36, 96-102.

Chen, M.-F., \& Tung, P.-J. (2009). The moderating effect of perceived lack of facilities on consumers' recycling intentions. Environment and Behavior.

Cheung, R., \& Vogel, D. (2013). Predicting user acceptance of collaborative technologies: An extension of the technology acceptance model for e-learning. Computers \& Education, 63, 160-175.

Cheung, S. F., Chan, D. K.-S., \& Wong, Z. S.-Y. (1999). Reexamining the theory of planned behavior in understanding wastepaper recycling. Environment and Behavior, 31(5), 587612.

Chin, W. W. (1998a). Commentary: Issues and opinion on structural equation modeling. MIS Quarterly, 22(1), vii-xvi.

Chin, W. W. (1998b). The Partial Least Squares Approach to Structural Equation Modeling. In G. A. Marcoulides (Ed.), Modern Methods for Business Research (pp. 295-336). Mahwah, United States: Taylor \& Francis Inc.

Cialdini, R. B., \& Goldstein, N. J. (2004). Social influence: Compliance and conformity. Annual Review of Psychology, 55, 591-621.

Cialdini, R. B., Kallgren, C. A., \& Reno, R. R. (1991). A focus theory of normative conduct: A theoretical refinement and reevaluation of the role of norms in human behavior. Advances in Experimental Social Psychology, 24(20), 1-243.

Cialdini, R. B., \& Trost, M. R. (1998). Social influence: Social norms, conformity and compliance. In L. Gardner, G. Daniel, \& S. T. Fiske (Eds.), The Handbook of Social Psychology: Oxford University Press.

Cohen, J. (1988). Statistical Power Analysis for the Behavioral Sciences: L. Erlbaum Associates.

Comber, R., \& Thieme, A. (2013). Designing beyond habit: Opening space for improved recycling and food waste behaviors through processes of persuasion, social influence and aversive affect. Personal and Ubiquitous Computing, 17(6), 1197-1210.

Conner, M., \& Armitage, C. J. (1998). Extending the theory of planned behavior: A review and avenues for further research. Journal of Applied Social Psychology, 28(15), 14291464.

Dahab, D. J., Gentry, J. W., \& Su, W. (1995). New ways to reach non-recyclers: An extension of the model of reasoned action to recycling behaviors. NA-Advances in Consumer Research, 22, 251-256.

Davies, J., Foxall, G., \& Pallister, J. (2002). Beyond the intention-behaviour mythology an integrated model of recycling. Marketing theory, 2(1), 29-113.

De Jaeger, S., Eyckmans, J., Rogge, N., \& Van Puyenbroeck, T. (2011). Wasteful wastereducing policies? The impact of waste reduction policy instruments on collection and processing costs of municipal solid waste. Waste Management, 31(7), 1429-1440.

Do Valle, P. O., Rebelo, E., Reis, E., \& Menezes, J. (2005). Combining behavioral theories to predict recycling involvement. Environment and Behavior, 37(3), 364-396.

Faul, F., Erdfelder, E., Lang, A.-G., \& Buchner, A. (2007). G*Power 3: A flexible statistical power analysis program for the social, behavioral, and biomedical sciences. Behavior Research Methods, 39(2), 175-191.

Fishbein, M., \& Ajzen, I. (1975). Belief, Attitude, Intention, and Behavior: An Introduction to Theory and Research: Addison-Wesley Pub. Co.

Follows, S. B., \& Jobber, D. (2000). Environmentally responsible purchase behaviour: A test of a consumer model. European Journal of Marketing, 34(5/6), 723-746.

Fornara, F., Carrus, G., Passafaro, P., \& Bonnes, M. (2011). Distinguishing the sources of normative influence on proenvironmental behaviors: The role of local norms in 
household waste recycling. Group Processes \& Intergroup Relations, 14(5), 623-635. doi: $10.1177 / 1368430211408149$

Fornell, C., \& Larcker, D. F. (1981). Evaluating structural equation models with unobservable variables and measurement error. Journal of Marketing Research, 18(1), 39-50.

Fransson, N., \& Gärling, T. (1999). Environmental concern: Conceptual definitions, measurement methods, and research findings. Journal of Environmental Psychology, 19(4), 369-382.

Gärling, T., Fujii, S., Gärling, A., \& Jakobsson, C. (2003). Moderating effects of social value orientation on determinants of proenvironmental behavior intention. Journal of Environmental Psychology, 23(1), 1-9.

Goddard, H. C. (1995). The benefits and costs of alternative solid waste management policies. Resources, Conservation and Recycling, 13(3), 183-213.

González-Torre, P. L., \& Adenso-Díaz, B. (2005). Influence of distance on the motivation and frequency of household recycling. Waste Management, 25(1), 15-23.

Hair, J. F., Black, W. C., Babin, B. J., \& Anderson, R. E. (2013). Multivariate Data Analysis: Pearson Education, Limited.

Hair, J. F., Ringle, C. M., \& Sarstedt, M. (2011). PLS-SEM: Indeed a silver bullet. The Journal of Marketing Theory and Practice, 19(2), 139-152.

Harland, P., Staats, H., \& Wilke, H. A. (1999). Explaining proenvironmental intention and behavior by personal norms and the theory of planned behavior. Journal of Applied Social Psychology, 29(12), 2505-2528.

Heath, Y., \& Gifford, R. (2002). Extending the theory of planned behavior: predicting the use of public transportation. Journal of Applied Social Psychology, 32(10), 2154-2189.

Henseler, J., Ringle, C. M., \& Sinkovics, R. R. (2009). The use of Partial Least Squares Path Modeling in International Marketing. Advances in International Marketing, 20, 277-319.

Henseler, J., \& Sarstedt, M. (2013). Goodness-of-fit indices for partial least squares path modeling. Computational Statistics, 28(2), 565-580.

Hornik, J., Cherian, J., Madansky, M., \& Narayana, C. (1995). Determinants of recycling behavior: A synthesis of research results. The Journal of Socio Economics, 24(1), 105127.

Huffman, A. H., Van Der Werff, B. R., Henning, J. B., \& Watrous-Rodriguez, K. (2014). When do recycling attitudes predict recycling? An investigation of self-reported versus observed behavior. Journal of Environmental Psychology, 38, 262-270.

Jöreskog, K. G., \& Sörbom, D. (1989). LISREL 7: A guide to the program and applications: Spss.

Jöreskog, K. G., \& Wold, H. (1982). The ML and PLS techniques for modeling with latent variables: Historical and comparative aspects. In K. G. Jöreskog \& H. Wold (Eds.), System Under Indirect Observation: causality, structure, prediction (pp. 263-270). Amsterdam; New York: ELSEVIER SCIENCE \& TECHNOLOGY.

Kaiser, F. G. (2006). A moral extension of the theory of planned behavior: Norms and anticipated feelings of regret in conservationism. Personality and Individual Differences, 41(1), 71-81.

Kaiser, F. G., Doka, G., Hofstetter, P., \& Ranney, M. A. (2003). Ecological behavior and its environmental consequences: A life cycle assessment of a self-report measure. Journal of Environmental Psychology, 23(1), 11-20.

Knussen, C., \& Yule, F. (2008). "I'm Not in the Habit of Recycling" The Role of Habitual Behavior in the Disposal of Household Waste. Environment and Behavior, 40(5), 683702 . 
Knussen, C., Yule, F., MacKenzie, J., \& Wells, M. (2004). An analysis of intentions to recycle household waste: The roles of past behaviour, perceived habit, and perceived lack of facilities. Journal of Environmental Psychology, 24(2), 237-246.

Lam, T., Baum, T., \& Pine, R. (2003). Subjective norms: effects on job satisfaction. Annals of Tourism Research, 30(1), 160-177.

Latan, H., \& Ghozali, I. (2012). Partial least Squares: Concept and application path modeling using program XLSTAT-PLS for empirical research, BP UNDIP.

Lu, I. R., Kwan, E., Thomas, D. R., \& Cedzynski, M. (2011). Two new methods for estimating structural equation models: An illustration and a comparison with two established methods. International Journal of research in Marketing, 28(3), 258-268.

Mahmud, S. N. D., \& Osman, K. (2010). The determinants of recycling intention behavior among the Malaysian school students: an application of theory of planned behaviour. Procedia-Social and Behavioral Sciences, 9, 119-124.

Mannetti, L., Pierro, A., \& Livi, S. (2004). Recycling: Planned and self-expressive behaviour. Journal of Environmental Psychology, 24(2), 227-236.

Manstead, A. S. R. (2000). The role of moral norm in the attitude-behaviour relation. In D. J. Terry \& M. A. Hogg (Eds.), Attitude, behaviour, and social context. The role of norms and group membership (pp. 11-30). Mahwah; NY: Lawrence Erlbaum.

Nolan, J. M., Schultz, P. W., Cialdini, R. B., Goldstein, N. J., \& Griskevicius, V. (2008). Normative social influence is underdetected. Personality and Social Psychology Bulletin, 34(7), 913-923.

Ohanian, R. (1990). Construction and validation of a scale to measure celebrity endorsers' perceived expertise, trustworthiness, and attractiveness. Journal of Advertising, 39-52.

Park, J., \& Ha, S. (2014). Understanding consumer recycling behavior: Combining the theory of planned behavior and the norm activation model. Family and Consumer Sciences Research Journal, 42(3), 278-291.

Povey, R., Conner, M., Sparks, P., James, R., \& Shepherd, R. (2000). Application of the Theory of Planned Behaviour to two dietary behaviours: Roles of perceived control and self-efficacy. British Journal of Health Psychology, 5(2), 121-139. doi: 10.1348/135910700168810

Ramayah, T., Lee, J. W. C., \& Lim, S. (2012). Sustaining the environment through recycling: An empirical study. Journal of Environmental Management, 102, 141-147.

Reinartz, W., Haenlein, M., \& Henseler, J. (2009). An empirical comparison of the efficacy of covariance-based and variance-based SEM. International Journal of research in Marketing, 26(4), 332-344.

Ringle, C. M., Wende, S., \& Will, S. (2005). SmartPLS 2.0 (M3) Beta, Hamburg.

Roccas, S., Sagiv, L., Schwartz, S. H., \& Knafo, A. (2002). The big five personality factors and personal values. Personality and social psychology bulletin, 28(6), 789-801.

Saphores, J.-D. M., Ogunseitan, O. A., \& Shapiro, A. A. (2012). Willingness to engage in a pro-environmental behavior: An analysis of e-waste recycling based on a national survey of U.S. households. Resources, Conservation and Recycling, 60, 49-63.

Schultz, P. W., Nolan, J. M., Cialdini, R. B., Goldstein, N. J., \& Griskevicius, V. (2007). The constructive, destructive, and reconstructive power of social norms. Psychological Science, 18(5), 429-434.

Schwartz, S. H. (1977). Normative Influences on Altruism. In B. Leonard (Ed.), Advances in Experimental Social Psychology (Vol. Volume 10, pp. 221-279): Academic Press.

Schwartz, S. H., \& Howard, J. A. (1981). A normative decision making model of altruism. In J. P. PRushton \& R. M. Sorrentino (Eds.), Altruism and helping behavior: Social, personality, and developmental perspectives (pp. 189-211). Hillsdale, NJ: Erlbaum. 
Sidique, S. F., Lupi, F., \& Joshi, S. V. (2010). The effects of behavior and attitudes on dropoff recycling activities. Resources, Conservation and Recycling, 54(3), 163-170.

Smallbone, T. (2005). How can domestic households become part of the solution to England's recycling problems? Business Strategy and the Environment, 14(2), 110-122. doi: $10.1002 /$ bse. 442

Stern, P. C., Dietz, T., Kalof, L., \& Guagnano, G. A. (1995). Values, beliefs, and proenvironmental action: Attitude formation toward emergent attitude objects. Journal of Applied Social Psychology, 25, 1611-1636.

Taylor, S., \& Todd, P. (1995a). An Integrated Model of Waste Management Behavior: A Test of Household Recycling and Composting Intentions. Environment and Behavior, 27(5), 603-630. doi: 10.1177/0013916595275001

Taylor, S., \& Todd, P. (1995b). Understanding Household Garbage Reduction Behavior: A Test of an Integrated Model. Journal of Public Policy \& Marketing, 14(2), 192-204.

Tencati, A., Pogutz, S., Moda, B., Brambilla, M., \& Cacia, C. (2016). Prevention policies addressing packaging and packaging waste: Some emerging trends. Waste Management, $56,35-45$.

Tenenhaus, M., Vinzi, V. E., Chatelin, Y.-M., \& Lauro, C. (2005). PLS path modeling. Computational Statistics \& Data Analysis, 48(1), 159-205.

Thøgersen, J. (1996). Recycling and morality a critical review of the literature. Environment and Behavior, 28(4), 536-558.

Thomas, C., \& Sharp, V. (2013). Understanding the normalisation of recycling behaviour and its implications for other pro-environmental behaviours: a review of social norms and recycling. Resources, Conservation and Recycling, 79, 11-20.

Tonglet, M., Phillips, P. S., \& Read, A. D. (2004). Using the Theory of Planned Behaviour to investigate the determinants of recycling behaviour: a case study from Brixworth, UK. Resources, Conservation and Recycling, 41(3), 191-214.

Turaga, R. M. R., Howarth, R. B., \& Borsuk, M. E. (2010). Pro-environmental behavior. Annals of the New York Academy of Sciences, 1185(1), 211-224.

Vining, J., \& Ebreo, A. (1990). What makes a recycler? A comparison of recyclers and nonrecyclers. Environment and Behavior, 22(1), 55-73.

Vining, J., \& Ebreo, A. (1992). Predicting recycling behavior from global and specific environmental attitudes and changes in recycling opportunities1. Journal of Applied Social Psychology, 22(20), 1580-1607.

Voss, K. E., Spangenberg, E. R., \& Grohmann, B. (2003). Measuring the Hedonic and Utilitarian Dimensions of Consumer Attitude. Journal of Marketing Research, 40(3), 310-320.

Wan, C., Cheung, R., \& Shen, G. Q. (2012). Recycling attitude and behaviour in university campus: a case study in Hong Kong. Facilities, 30(13/14), 630-646.

Wan, C., Shen, G. Q., \& Yu, A. (2014). The role of perceived effectiveness of policy measures in predicting recycling behaviour in Hong Kong. Resources, Conservation and Recycling, 83, 141-151.

White, K. M., Smith, J. R., Terry, D. J., Greenslade, J. H., \& McKimmie, B. M. (2009). Social influence in the theory of planned behaviour: The role of descriptive, injunctive, and in-group norms. British Journal of Social Psychology, 48(1), 135-158.

Wilson, D. C. (1996). Stick or carrot?: The use of policy measures to move waste management up the hierarchy. Waste management \& research, 14(4), 385-398.

Wilson, D. C., Rodic, L., Scheinberg, A., Velis, C. A., \& Alabaster, G. (2012). Comparative analysis of solid waste management in 20 cities. Waste management \& research, 30(3), 237-254. 
Yiu, C. Y., \& Xu, S. Y. (2012). A tenant-mix model for shopping malls. European Journal of Marketing, 46(3/4), 524-541. 


\section{Appendix 1}

\begin{tabular}{|c|c|c|}
\hline Constructs & Indicators & \\
\hline \multirow{6}{*}{$\begin{array}{l}\text { Attitude } \\
\text { (ATT) }\end{array}$} & ATT1 & Recycling is good. \\
\hline & ATT2 & Recycling is useful. \\
\hline & ATT3 & Recycling is rewarding. \\
\hline & ATT4 & Recycling is responsible. \\
\hline & ATT5 & Recycling is sensible. \\
\hline & ATT6 & Recycling is hygienic. \\
\hline \multirow{6}{*}{$\begin{array}{l}\text { Subjective Norm } \\
\text { (SN) }\end{array}$} & SN1 & Most people who are important to me think I should recycle. \\
\hline & $\mathrm{SN} 2$ & Most people who are important to me would approve of my recycling. \\
\hline & SN3 & My friends expect me to recycle household materials. \\
\hline & SN4 & My family expects me to recycle household materials. \\
\hline & SN5 & Media influences me to recycle recyclables. \\
\hline & SN6 & Environmental groups influence me to recycle recyclables. \\
\hline \multirow{7}{*}{$\begin{array}{l}\text { Perceived Behavioral } \\
\text { Control } \\
\text { (PBC) }\end{array}$} & PBC1 & I have plenty of opportunities to recycle. \\
\hline & $\mathrm{PBC} 2$ & Recycling is convenient. \\
\hline & $\mathrm{PBC} 3$ & Recycling is easy. \\
\hline & PBC4 & I know where to take my household waste for recycling. \\
\hline & PBC5 & I know how to recycle my household waste. \\
\hline & PBC6 & I have enough time to sort the materials for recycling. \\
\hline & $\mathrm{PBC} 7$ & I have enough space to store the materials for recycling. \\
\hline \multirow{6}{*}{$\begin{array}{l}\text { Awareness of } \\
\text { Consequences } \\
\text { (AC) }\end{array}$} & $\mathrm{AC} 1$ & Recycling reduces pollution. \\
\hline & $\mathrm{AC} 2$ & Recycling reduces wasteful use of landfills. \\
\hline & $\mathrm{AC} 3$ & Recycling improves environmental quality. \\
\hline & AC4 & Recycling saves energy. \\
\hline & AC5 & Recycling saves money. \\
\hline & AC6 & Recycling creates a better environment for future generations. \\
\hline \multirow{5}{*}{$\begin{array}{l}\text { Moral Norm } \\
(\mathrm{MN})\end{array}$} & MN1 & I feel I should not waste anything if it could be used again. \\
\hline & MN2 & It would be wrong of me not to recycle my household waste. \\
\hline & $\mathrm{MN} 3$ & I would feel guilty if I did not recycle my household waste. \\
\hline & MN4 & Not recycling goes against my principles. \\
\hline & MN5 & Everybody should share the responsibility to recycle household waste. \\
\hline \multirow{3}{*}{$\begin{array}{l}\text { Recycling Intention } \\
\text { (RI) }\end{array}$} & RI1 & I intend to recycle my recyclables in the next four weeks. \\
\hline & RI2 & I will recycle my recyclables every time I have it for disposal. \\
\hline & RI3 & I am willing to participate in the recycling scheme in the future. \\
\hline
\end{tabular}

